\title{
Assessment Scales, Associated Factors and the Quality of Life Score in Pregnant Women in Iran
}

\author{
Farideh Kazemi ${ }^{1}$, Fatemeh Nahidi ${ }^{1} \&$ Nourossadat Kariman ${ }^{1}$ \\ ${ }^{1}$ Department of Midwifery \& Reproductive Health, School of Nursing \& Midwifery, Shahid Beheshti University \\ of Medical Sciences, Tehran, Iran \\ Correspondence: Fatemeh Nahidi, Department of Midwifery \& Reproductive Health, School of Nursing \& \\ Midwifery, Shahid Beheshti University of Medical Sciences, Tehran, Iran. Tel: 98-912-100-9191. E-mail: \\ nahidifateme@yahoo.com
}

Received: January 7, 2016 Accepted: February 18, 2016 Online Published: February 29, 2016

doi:10.5539/gjhs.v8n11p127 URL: http://dx.doi.org/10.5539/gjhs.v8n11p127

\begin{abstract}
Women experience physical, chemical, endocrine gland and organ changes during pregnancy that limit their activities and reduce their quality of life. The present study was conducted to investigate the quality of life in pregnant women in Iran, the assessment scales used to measure this variable and the factors associated with it.

The present study searched databases including Science Direct, PubMed, Scopus, SID, Iranmedex, Mahiran, IranDoc and Google Scholar using keywords such as pregnant women, Iran, quality of life, pregnancy and prenatal and their Persian equivalents to find relevant articles conducted in Iran and ultimately found 20 articles to review without any regard for their time, language and publication site.

Studies conducted in Iran to assess the quality of life in pregnant women have used four tools, including the SF-36, the WHOQOL-BRIEF, the SF-12 and the Nausea and Vomiting of Pregnancy-Specific Health-Related Quality of Life Questionnaire. The mean quality of life score obtained using these different tools varied from $61.18 \pm 13.21$ to $66.48 \pm 15.57$. Social support, socioeconomic status, the pregnancy being wanted, satisfaction with life and sexual function were related directly to the quality of life, while prenatal mental disorders, the severity of pregnancy nausea and vomiting and sleep disorders were related inversely to it.

Given the lack of a specific tool designed to assess the quality of life in pregnant women, general tools were used for its assessment. Further studies are thus required to design a specific localized tool and to also assess the relationship between the quality of life and its associated factors.
\end{abstract}

Keywords: Quality of life, pregnancy, tools, Iran

\section{Introduction}

Pregnancy is a major event in a woman's life. Women experience physical, chemical, endocrine gland and organ changes during pregnancy (Hama et al., 2008; Li et al., 2012) and also symptoms such as fatigue, nausea, vomiting, headache, loss of appetite, heartburn, hemorrhoids and shortness of breath (Makvandi \& Etemadi Kermani, 2012). The complexity of pregnancy-related changes are not restricted to physical factors and psychosocial factors are also involved (Calou et al., 2014) and help limit women's activities and reduce their quality of life during this period (Forger, Ostensen, Schumacher, \& Villiger, 2005; Hama et al., 2008; Ramírez-Vélez, 2011; Vachkova, Jezek, Mares, \& Moravcova, 2013; Vallim et al., 2011).

Since 1948, when the World Health Organization (WHO) defined health as "a state of complete physical, mental, and social well-being and not merely the absence of disease or infirmity", the quality of life has become a more important issue in health care and research activities (Testa \& Simonson, 1996). The WHO defines quality of life as "an individual's perception of their position in life in the context of the culture and value system in which they live and in relation to their goals, expectations and standards and concerns" (World Health Organization, 1996).

In recent decades, researchers have been more interested in the concept of quality of life, particularly in the context of health care, and have also shown a growing interest in the evaluation of quality of life through clinical studies designed to assess the relative efficacy of pregnancy and postpartum preventive and treatment programs (Higginson \& Carr, 2001). Although pregnancy care aims at favorable maternal and neonatal outcomes, it is important to note that a woman's lifestyle during pregnancy is affected by the changes occurring during this 
period (Ramírez-Vélez, 2011). In developed countries, pregnancy and postpartum care are not only aimed at prevention, diagnosis and management of pregnancy problems and complications, but also at more comprehensive goals such as the encouragement of mental adaptation to pregnancy, suggesting a focus on women's quality of life and psychological state during this period (Mousavi, Mortazavi, Chaman, \& Ajami, 2012).

Although pregnancy has become more recognized as a special period in recent years, conducting further studies on factors that affect the quality of life in pregnant women can help adopt the right strategies for promoting maternal health. The limited data available on the physical, psychological and social changes experienced by pregnant women indicates the need for a greater focus on the quality of life in this group of the population and the associated domains that can change (Calou et al., 2014). Given the importance of quality of life during pregnancy and its effect on maternal and neonatal health, the present study was designed to assess the quality of life in Iranian pregnant women and to identify its associated factors and the tools used for its assessment.

\section{Method}

The present systematic review collected its data searched databases such as Science Direct, PubMed, Scopus, SID, Iranmedex, Mahiran, IranDoc and Google Scholar using keywords such as quality of life, Iran, pregnant women, prenatal and pregnancy and their Persian equivalents both separately and in combination. All the descriptive, control-case and cohort studies conducted on the quality of life in Iranian pregnant women published in domestic and foreign journals in either Persian or English were included in the study without any time constraints. The eligibility of the articles for inclusion in the study was determined using the Strobe checklist.

A total of 1804 articles was retrieved at first; 1753 of them, however, were deemed irrelevant and were thus excluded after a review of their titles and abstracts, leaving 51 articles for the second stage of screening. At this stage, the full text of the articles was reviewed and 31 articles were deemed repetitive and were thus excluded, leaving a total of 20 articles for the final assessment. The assessments were performed independently by two reviewers and the article would be included in the absence of a consensus between the reviewers (figure 1).

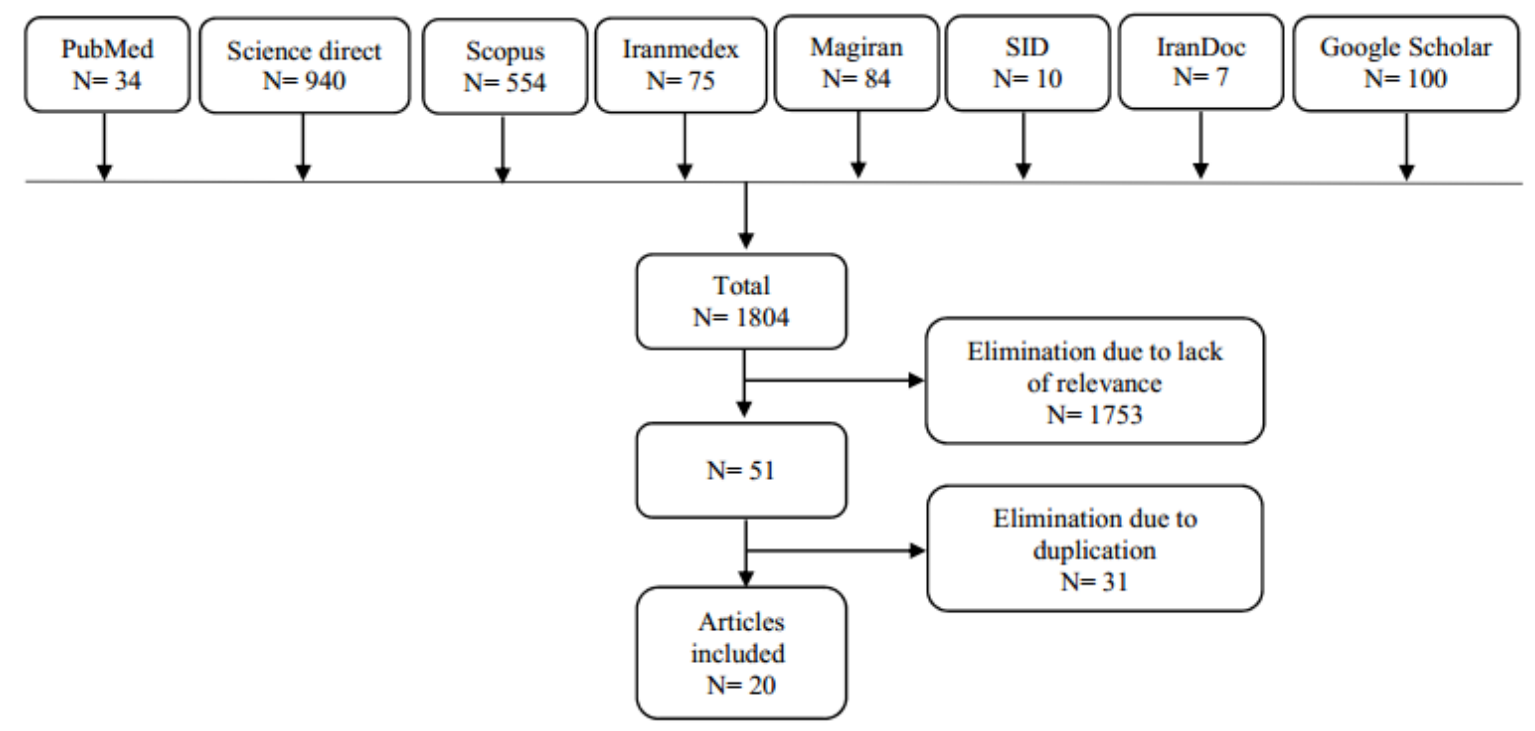

Figure 1. Flowchart of entering the studies

\section{Results}

The results obtained are classified and shown in Table 1. Of the 20 articles selected, 8 were in English and the rest were in Persian. The articles had used four tools to assess the quality of life in pregnant women, including the SF-36, the WHOQOL-BRIEF, the SF-12 and the Nausea and Vomiting of Pregnancy-Specific Health-Related Quality of Life Questionnaire. The results are presented in three sections, including the mean score of the quality of life, the assessment tool used and the factors associated with quality of life during pregnancy. 
Table 1. Systematic Review of Iranian studies on the quality of life during pregnancy

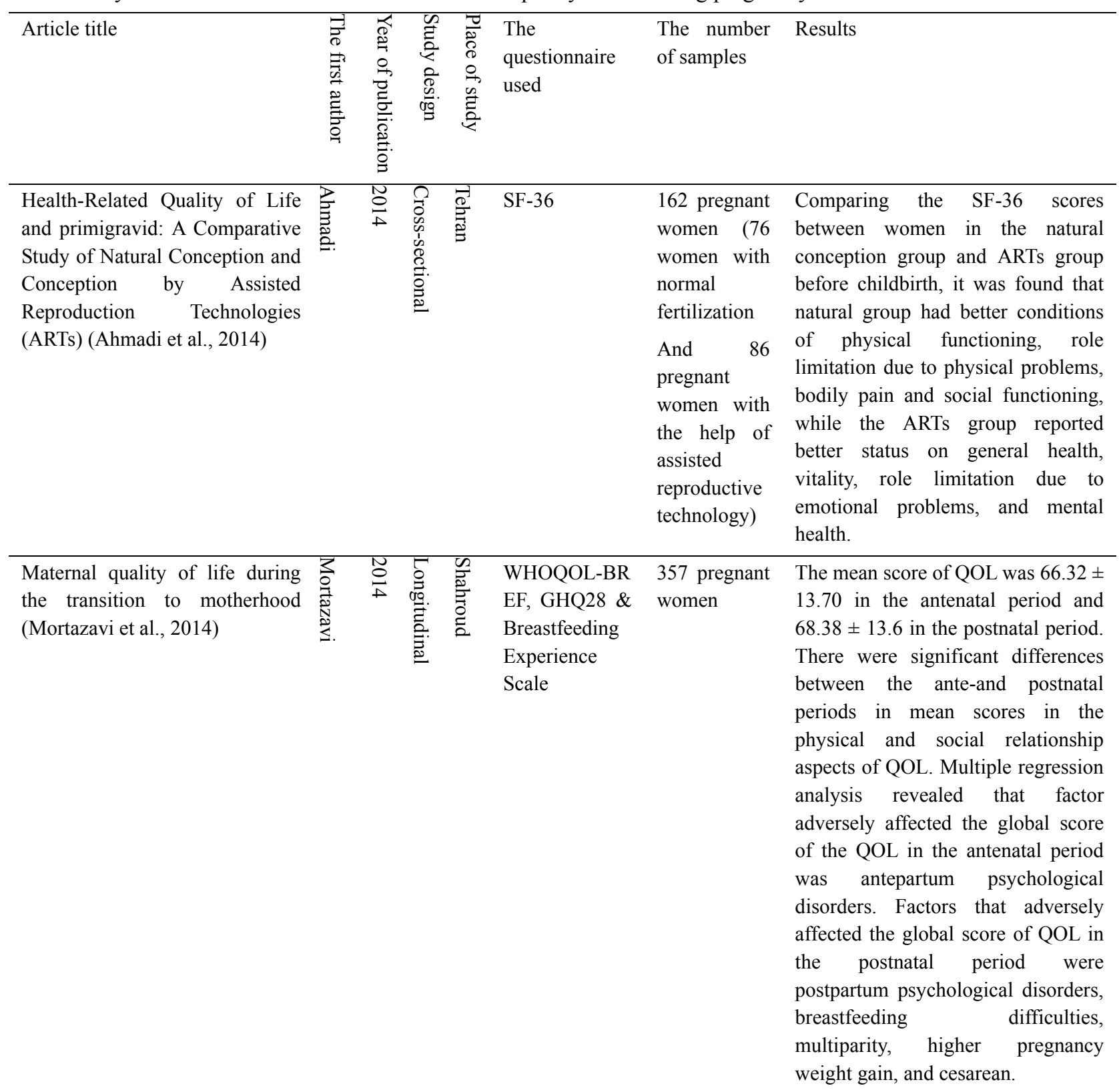




\begin{tabular}{|c|c|c|c|c|c|}
\hline $\begin{array}{l}\text { The quality of life in pregnant } \\
\text { women in Farokhshahr city, } \\
2012 \text { (Zahedi \& Deris, 2014) }\end{array}$ & $\stackrel{\widetilde{O}}{\vec{D}}$ & $\begin{array}{l}\Omega \\
0 \\
0 \\
0 \\
1 \\
0 \\
0 \\
0 \\
0 \\
0 \\
0 \\
0\end{array}$ & $\begin{array}{l}\text { Tे } \\
\stackrel{0}{0} \\
0 \\
\overline{\hat{\sigma}} \\
\overrightarrow{0} \\
\stackrel{2}{2}\end{array}$ & SF-36 & $\begin{array}{l}170 \text { pregnant } \\
\text { women }\end{array}$ \\
\hline
\end{tabular}

The mean score of quality of life in the different dimensions of health situation was higher than moderate rate, and the total score of quality of life was $66.48 \pm 15.57$. There was a significant and inversely relationship between age and gestational age with some domains of quality of life. The mean score for quality of life during pregnancy with two times, unwanted pregnancy and employed mothers was less than once pregnancies, wanted pregnancy and unemployed mother. There was no significant relationship between the level of woman education, the level of husband education, husband's job, spouse's support and household income with a total score of quality of life.

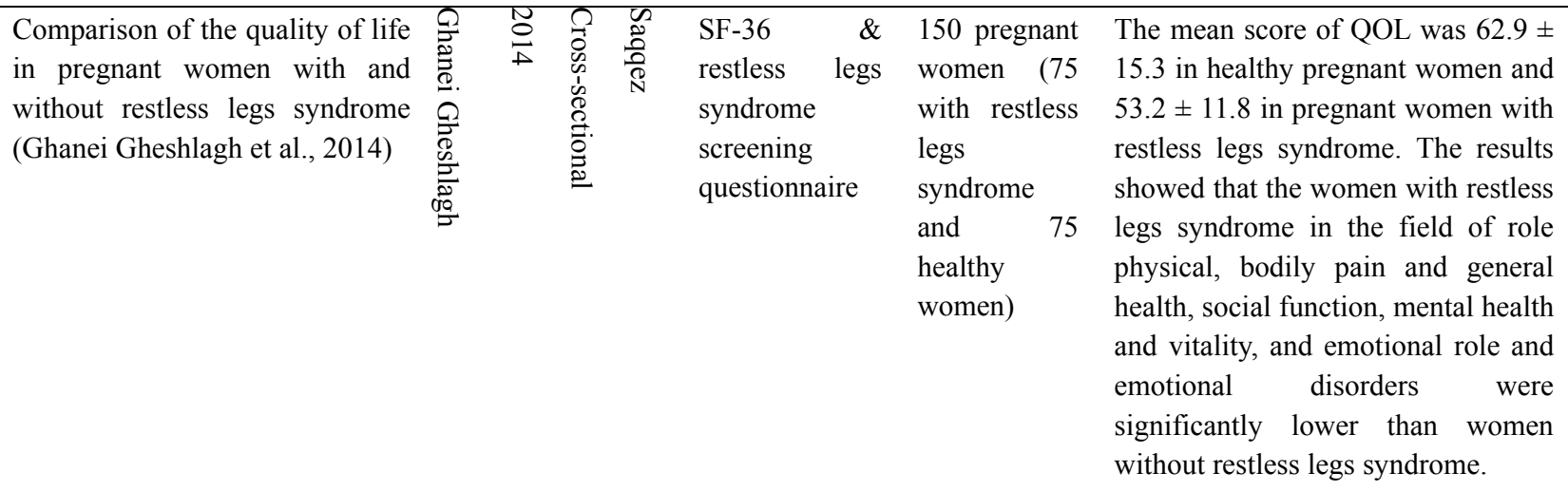

\begin{tabular}{|c|c|c|c|c|c|c|}
\hline $\begin{array}{l}\text { Comparison of quality of life in } \\
\text { low risk pregnant with high risk } \\
\text { pregnant women in perinatology } \\
\text { clinic of kowsar ward Shahid } \\
\text { Motahari hospital in Urmia } 2013 \\
\text { (Mohaddesi et al., 2014) }\end{array}$ & 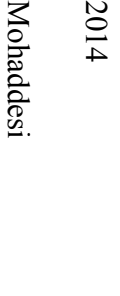 & 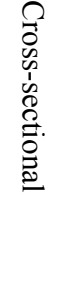 & @ & SF-36 & $\begin{array}{l}100 \text { pregnant } \\
\text { women (each } \\
\text { group } 50 \text { ) }\end{array}$ & $\begin{array}{l}\text { There was no significant difference } \\
\text { in the quality of life between the two } \\
\text { groups, although the score of quality } \\
\text { of life in women with high-risk } \\
\text { pregnancy was often lower than the } \\
\text { scores of women with low-risk } \\
\text { pregnancy. }\end{array}$ \\
\hline
\end{tabular}

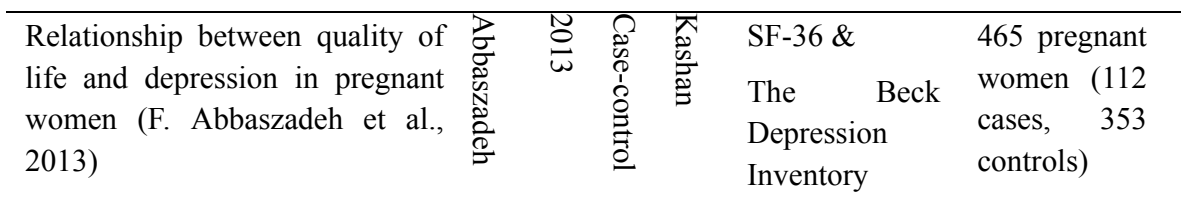

The mean score of QOL was $52.85 \pm$ 11.80 in depressed women and $63.72 \pm 12.86$ in non-depressed women. There was an inverse relationship between quality of life and depression in pregnancy. Average scores in all eight domains of quality of life were significantly lower in depressed pregnant women compared to non-depressed women. The strongest relationship was observed between depression and vitality, mental health and social functioning. 


\begin{tabular}{|c|c|c|c|c|c|}
\hline $\begin{array}{l}\text { Evaluation of sexual function, } \\
\text { quality of life, and mental and } \\
\text { physical health in pregnant } \\
\text { women (Nik-Azin et al., 2013) }\end{array}$ & $\begin{array}{l}\widetilde{\sigma} \\
\text { w }\end{array}$ & $\begin{array}{l}\text { ?. } \\
0 \\
0 \\
1 \\
0 \\
0 \\
\stackrel{0}{0} \\
0 \\
0\end{array}$ & $\begin{array}{l}\overrightarrow{0} \\
\stackrel{0}{*} \\
\hat{\theta}\end{array}$ & $\begin{array}{l}\text { WHOQOL-BR } \\
\text { IEF, FSFI \& } \\
\text { DASS-21 }\end{array}$ & $\begin{array}{l}150 \text { pregnant } \\
\text { women }\end{array}$ \\
\hline
\end{tabular}

Obtained results showed that $39.3 \%$ pregnant women were "very dissatisfied", $16.7 \%$ women were "moderately dissatisfied", $\quad 42.7 \%$ women were "both satisfied and unsatisfied", only $1.3 \%$ women were relatively satisfied, and no one was "very satisfied". There is a significantly negative weak correlation between female sexual function with anxiety and depression, while there is a significantly positive weak correlation between female sexual function with the general quality of life, psychological health and environment dimensions. Only depression predicts female sexual function significantly. The women more than 10 years passed of their marriage showed more sexual satisfaction compared to those less than 10 years passed of their marriage.

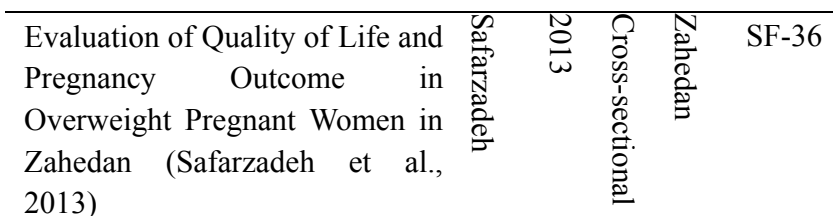

440 pregnant Physical functioning, role limitation women (220 due to physical problems and Bodily normal pain was lower in overweight weights and women than in normal weight 220 overweight) women in the first trimester of pregnancy. The all of domain of quality of life decreased during pregnancy and was lower in overweight than in normal weight pregnant women in the third trimester of pregnancy.

\begin{tabular}{|c|c|c|c|c|}
\hline $\begin{array}{l}\text { Quality of life in pregnant } \overline{\widetilde{N}} \\
\text { women with a sleep disorder } \\
\text { (Rezaei et al., 2013) }\end{array}$ & $\begin{array}{l}\mathrm{N} \\
\stackrel{0}{0} \\
\stackrel{\omega}{*}\end{array}$ & $\begin{array}{l}\Omega \\
0 \\
0 \\
0 \\
1 \\
0 \\
0 \\
0 \\
0 \\
0 \\
0\end{array}$ & $\begin{array}{l}3 \\
\stackrel{2}{\hat{2}} \\
0\end{array}$ & $\begin{array}{l}\text { WHOQOL-BR } \\
\text { EF \& PSQI }\end{array}$ \\
\hline
\end{tabular}

100 pregnant
women with
sleep
disorders in
the second
trimester

The results of Pearson and Spearman correlation test demonstrate that there was a significant relationship between the quality of life score and sleep quality score, but only within the domains of quality of life, there was a significant relationship between psychological health and sleep quality. There were significant differences between the job, education level, parity, and the spouse's support and life satisfaction with quality of life. The age and parity were significantly associated with the sleep quality score, but there were significant inverse related between age and parity to quality of life. 


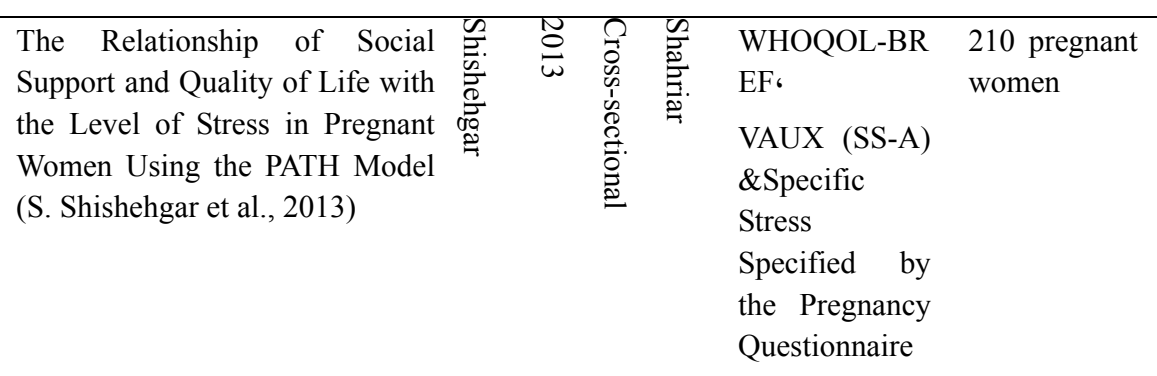

Mean scores were as follows; social support during pregnancy $17.2 \pm 3$, quality of life $64.4 \pm 11.3$, and pregnancy stress $43.6 \pm 20.1$. There was a significant correlation between social support and quality of life. According to our results, there was a significant correlation between socioeconomic status and quality of life and stress during pregnancy, but it didn't have any significant relationship with social support. Stress was inversely and significantly correlated with social support and quality of life. Also, social support showed direct and significant correlation with quality of life.

\begin{abstract}
Comparing the quality of life and psychological state of multiparous and primiparous women in the ante-and postnatal periods: A cohort study (Mousavi et al., 2012)
\end{abstract}

\begin{tabular}{|c|c|c|c|c|}
\hline 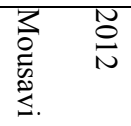 & $\stackrel{0}{\varrho}$ & $\begin{array}{l}\mathscr{\omega} \\
\overline{0} \\
\tilde{D}_{0} \\
0 \\
0 \\
0\end{array}$ & $\begin{array}{l}\text { WHOQOL-BR } \\
\text { EF \& GHQ28 }\end{array}$ & $\begin{array}{l}273 \text { pregnant } \\
\text { women }\end{array}$ \\
\hline
\end{tabular}

The mean score of quality of life during pregnancy and after delivery in nulliparous women was more than the multiparous women. The average score of the general health questionnaire were significantly lower in nulliparous women compared to multiparous women.

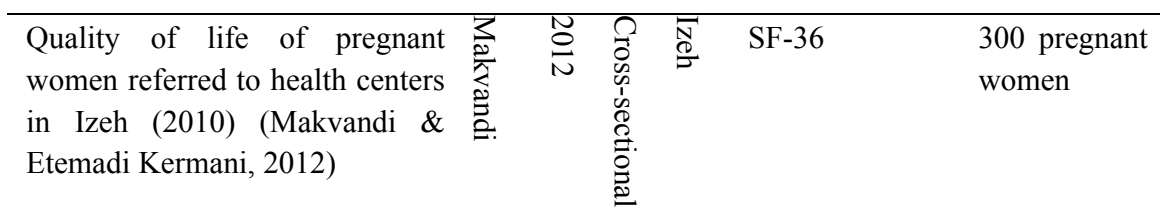

The mean score of quality of life in pregnant women was $62.9 \pm 17.3$. The highest score was related to social functioning and the lowest scores were related to the vitality and functional limitations due to physical problems. There was no significant association between women age, gestational age, parity, level of education and place of residence with the score of quality of life. The quality of life score was significantly lower in unwanted pregnancies than wanted pregnancies.

\begin{tabular}{|c|c|c|c|c|c|}
\hline $\begin{array}{l}\text { The Quality of Pregnant Women } \\
\text { Life with Nausea and Vomiting } \\
\text { (Jouybari L et al., 2012) }\end{array}$ & $\stackrel{\frac{N}{N}}{N}$ & $\begin{array}{l}0 \\
0 \\
0 \\
0 \\
1 \\
0 \\
0 \\
0 \\
0 \\
0 \\
0\end{array}$ & $\begin{array}{c}0 \\
\stackrel{0}{0} \\
00 \\
0 \\
0\end{array}$ & $\begin{array}{l}\text { SF-36 \& } \\
\text { Rhodes index } \\
\text { to determine } \\
\text { the severity of } \\
\text { nausea and } \\
\text { vomiting }\end{array}$ & $\begin{array}{l}120 \text { pregnant } \\
\text { women }\end{array}$ \\
\hline
\end{tabular}

The mean score of quality of life in 60 percent of pregnant women was more than 50. There was a significant correlation between quality of life and severity of nausea and vomiting, mother's age, mother's education and father's education. Instead, there was no significant association between ethnicity, place of residence, occupation, household income, parity, pre-pregnancy and pregnancy BMI and gestational age with quality of life score. 


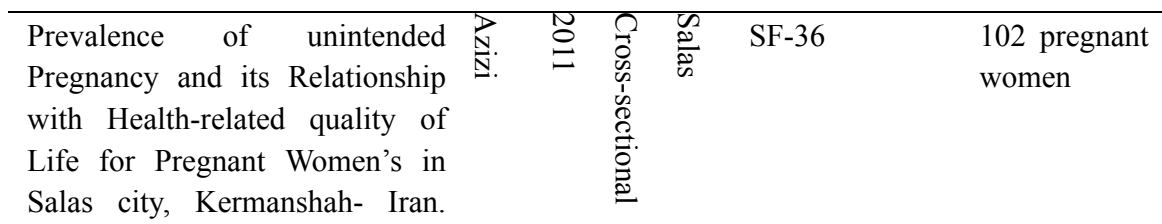

2007 (Azizi et al., 2011)
The prevalence of unwanted pregnancy in the study was $40.2 \%$. The mean score of QOL was $61.84 \pm$ 1 in wanted pregnancy and $46.5 \pm$ 8.4 in unwanted pregnancy. There was a significant correlation between quality of life and the type of pregnancy. The mean score of quality of life in psychological and physical dimensions in women with unwanted pregnancies were significantly lower than the wanted pregnancies.

\begin{tabular}{|c|c|c|c|}
\hline $\begin{array}{l}\text { Health related quality of life in } \\
\text { pregnant women: a comparison } \\
\text { between urban and rural } \\
\text { b } \\
\text { populations (Naseem et al., } \\
\text { 2011) }\end{array}$ & $\stackrel{N}{\ominus}$ & 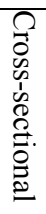 & $\begin{array}{l}\overline{0} \\
0 \\
03 \\
0 \\
0 \\
0\end{array}$ \\
\hline
\end{tabular}

179 pregnant Role limitations because of physical women problems, general health perceptions and role limitations because of emotional problems had statistically significantly lower scores in rural women as compared to urban women.

\begin{tabular}{|c|c|c|c|c|}
\hline \multirow[t]{2}{*}{$\begin{array}{l}\text { Association of vomiting in } \\
\text { pregnancy with body mass index } \\
\text { and quality of life (F. Shishehgar } \\
\text { \& Payman, 2010) }\end{array}$} & \multirow{2}{*}{\multicolumn{2}{|c|}{ 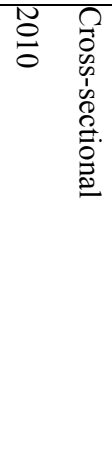 }} & \multirow[t]{2}{*}{$\begin{array}{l}\overrightarrow{0} \\
\stackrel{0}{*} \\
\hat{\theta}\end{array}$} & $\begin{array}{l}\text { Health related } \\
\text { quality of life } \\
\text { for nausea and } \\
\text { vomiting } \\
\text { questionnaire }\end{array}$ \\
\hline & & & & $\begin{array}{lr}\& \quad \text { Rhodes } \\
\text { index } \\
\text { determine the } \\
\text { severity of } \\
\text { nausea and } \\
\text { vomiting }\end{array}$ \\
\hline
\end{tabular}

\begin{tabular}{|c|c|c|c|c|}
\hline \multirow[t]{2}{*}{$\begin{array}{l}\text { Characteristics of nausea and } \\
\text { vomiting in pregnancy and its } \\
\text { association with quality of life } \\
\text { (F. Shishehgar \& Payman, 2009) }\end{array}$} & $\begin{array}{l}\text { No } \\
8 \\
8\end{array}$ & 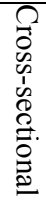 & $\begin{array}{l}\vec{\theta} \\
\stackrel{\theta}{E} \\
\hat{g}\end{array}$ & $\begin{array}{l}\text { Health related } \\
\text { quality of life } \\
\text { for nausea and } \\
\text { vomiting } \\
\text { questionnaire }\end{array}$ \\
\hline & & & & $\begin{array}{lr}\& & \text { Rhodes } \\
\text { index } & \text { to } \\
\text { determine the } \\
\text { severity of } \\
\text { nausea and } \\
\text { vomiting }\end{array}$ \\
\hline
\end{tabular}

140 pregnant The BMI was significantly lower in women the moderate and severe groups than the mild group. Patients in the moderate and severe groups reported a lower quality of life as compared to the mild group.

$\begin{array}{ll}220 \text { pregnant } & \begin{array}{l}\text { There was a significant correlation } \\ \text { women }\end{array} \\ \text { between the severity of nausea and } \\ \text { vomiting in all of the pregnancy } \\ \text { weeks with reducing the quality of } \\ \text { life score in the physical dimension } \\ \text { that this correlation was stronger in } \\ \text { weeks 4-7, 12-15 and 16-19. There } \\ \text { was a significant correlation } \\ \text { between the severity of nausea and } \\ \text { vomiting in all of the pregnancy } \\ \text { weeks with reducing the quality of } \\ \text { life score that this correlation was } \\ \text { stronger in weeks 4-7 and 12-15. }\end{array}$




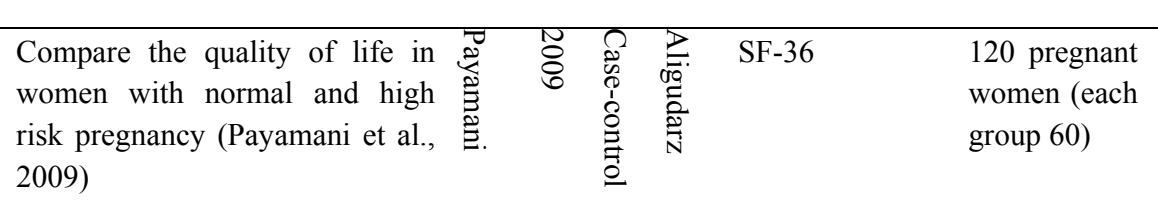
$56.31 \pm 15.44)$. There was a
significant difference between the two groups in terms of mental health, social functioning, general health and vitality. There were significant relationships between the age less than 18 years, twin pregnancy and diabetes to physical functioning and between hypothyroidism, anemia, breastfeeding, pregnancy with IVF and infertility history to limitation of physical functioning.

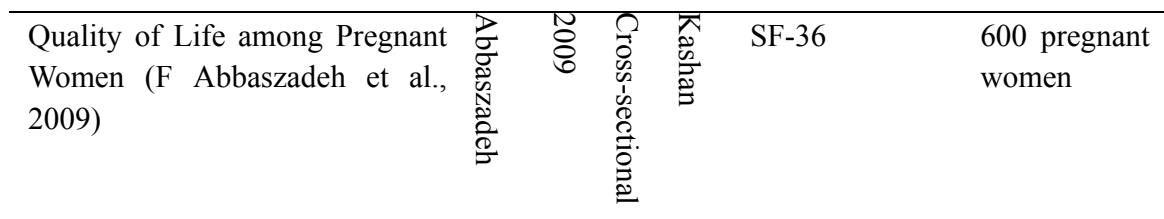

The mean score of the quality of life in pregnant women was $61.18 \pm$ 13.21. There was a significant difference in all domains of quality of life in pregnant women compared to Iranian female population except social function. There was an inverse relationship between quality of life and age, gestational age, number of pregnancies and parity and a direct relationship between quality of life and monthly household income, spouse's support, wanted pregnancy and life satisfaction.

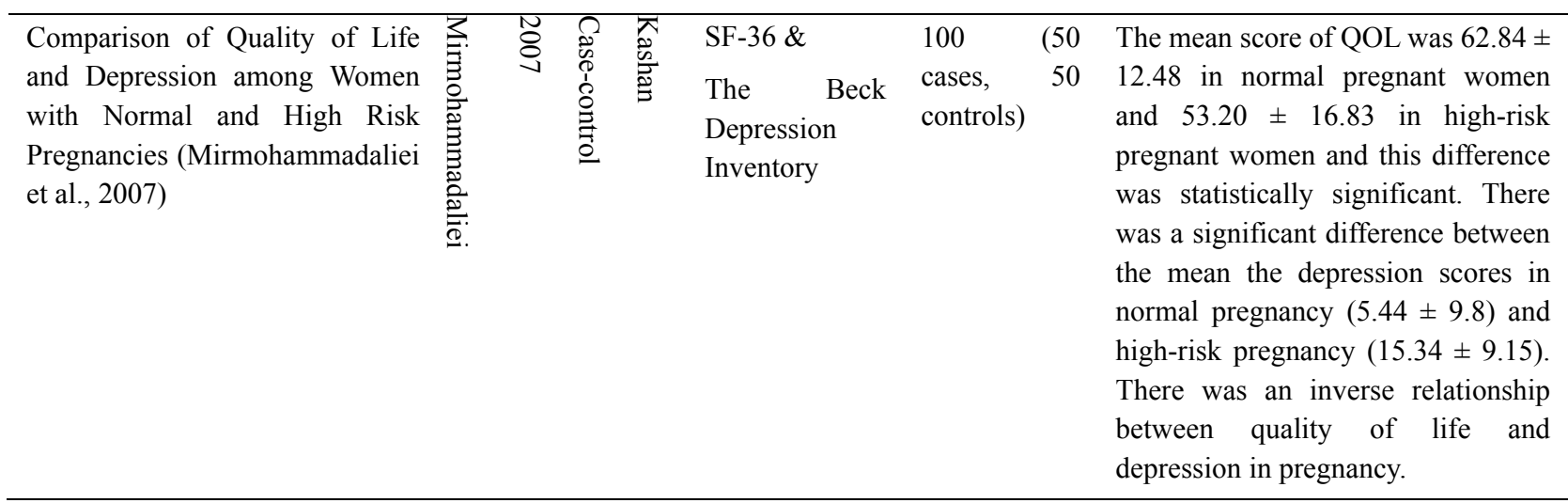

\subsection{The Mean Score of Quality of Life}

Of the 20 articles reviewed, 10 had reported a score for the quality of life in pregnant women. The results obtained in the 8 articles that had used the SF-36 were as follows:

The mean score of quality of life in pregnant women was $61.8 \pm 13.21$ in the study conducted by Abbasszadeh et al. in Kashan (F. Abbaszadeh, Baghery, \& Mehran, 2009), 62.9 \pm 17.3 in the study by Makvandi et al. in Izeh (Makvandi \& Etemadi Kermani, 2012), and 66.48 \pm 15.57 in the study by Zahedi et al. in Farokhshahr (Zahedi \& Deris, 2014). In a study conducted in Salas county, the mean score of quality of life was reported as $61.8 \pm 1$ in wanted pregnancies and as $46.2 \pm 8$ in unwanted pregnancies (Azizi, Amirian, pashaei, \& Amirian, 2011). In another study conducted in Saqqez, this figure was $62.9 \pm 15.3$ in healthy pregnant women and $53.2 \pm 11.8$ in 
women with restless leg syndrome (Ghanei Gheshlagh, Toloeipoor Lanjavani, Lazari, \& Moslemi, 2014). In their other study in Kashan, Abbasszadeh et al. reported the mean score of quality of life as $63.72 \pm 12.86$ in non-depressed pregnant women and as 52.85 11.8 in depressed pregnant women (F. Abbaszadeh et al., 2013).

Two of the studies compared quality of life in women with high-risk and normal pregnancies; Paymani et al. conducted their study in Aligudarz and reported this score as 35.79 \pm 14.67 in women with high-risk pregnancies and as 56.31 \pm 15.44 in women with normal pregnancies (Payamani et al., 2009); Mirmohammad Alaee et al. conducted their study in Kashan and reported these scores as $53.2 \pm 16.83$ and $62.82 \pm 12.48$, respectively (Mirmohammadaliei, Khakbazan, Kazemnejad, \& Abbaszadeh, 2007).

Two of the studies used the WHOQOL-BREF to examine the mean score of quality of life; Mortazavi et al. conducted their study in Shahrud and reported this score as 66.32 \pm 13.7 (Mortazavi, Mousavi, Chaman, \& Khosravi, 2014); Shishehgar et al. conducted their study in Shahriar and reported this score as $64.4 \pm 11.3$ (S. Shishehgar et al., 2013).

\subsection{Assessment Tool}

The SF-36 was the most commonly used tool for assessing quality of life in the studies reviewed in the present study, as it was used in 12 of the articles (F Abbaszadeh et al., 2009; F. Abbaszadeh et al., 2013; Ahmadi et al., 2014; Azizi et al., 2011; Ghanei Gheshlagh et al., 2014; Jouybari L, Sanagou A, \& Chehreh Gosha M, 2012; Makvandi \& Etemadi Kermani, 2012; Mirmohammadaliei et al., 2007; Mohaddesi, Bahadory, khalkhali, \& Baghi, 2014; Payamani et al., 2009; Safarzadeh, Boryri, Khojasteh, \& NavvabiRigi, 2013; Zahedi \& Deris, 2014). The SF-36 is a common tool used for the general assessment of health-related quality of life and consists of 8 subscales, including physical functioning (10 items), social role functioning ( 2 items), vitality (4 items), emotional role functioning ( 3 items), bodily pain ( 2 items), physical role functioning (4 items), mental health (5 items) and general health perceptions (5 items). The eighth item assesses perceived changes in general health over a one-year period (health transition). The questionnaire items are given scores of 0 to 100 , with higher scores indicating a better quality of life (Montazeri, Goshtasebi, Vahdaninia, \& Gandek, 2005; Nedjat, Montazeri, Holakouie, Mohammad, \& Majdzadeh, 2008). This questionnaire was first translated and validated in Iran by Montazeri et al. in 2005 (Montazeri et al., 2005). The tools used in the other articles included the WHOQOL-BREF, the Nausea and Vomiting of Pregnancy-Specific Health-Related Quality of Life Questionnaire and the SF-12; however, none of these questionnaire have been designed specifically for the assessment of quality of life during pregnancy.

\subsection{Factors Associated with Quality of Life}

According to the reviewed studies, various factors are directly and significantly related to the quality of life during pregnancy, including social support (S. Shishehgar et al., 2013), socioeconomic status (S. Shishehgar et al., 2013), the pregnancy being wanted (F. Abbaszadeh et al., 2009; Azizi et al., 2011; Makvandi \& Etemadi Kermani, 2012; Zahedi \& Deris, 2014), satisfaction with life (F Abbaszadeh et al., 2009; Rezaei, Moghadam, \& Saraylu, 2013) and sexual function (Nik-Azin et al., 2013). In contrast, factors such as prenatal mental disorders (F. Abbaszadeh et al., 2013; Mirmohammadaliei et al., 2007; Mortazavi et al., 2014; S. Shishehgar et al., 2013), the severity of pregnancy nausea and vomiting (Jouybari L et al., 2012; F. Shishehgar \& Payman, 2009, 2010) and sleep disorders (Ghanei Gheshlagh et al., 2014; Rezaei et al., 2013) are related inversely to the quality of life.

There were conflicting reports on the relationship between the quality of life during pregnancy and some other factors; for example, in some studies, the adequacy of the household income (F. Abbaszadeh et al., 2009), spouse's support (F. Abbaszadeh et al., 2009; Rezaei et al., 2013) and the woman's own (Jouybari L et al., 2012; Rezaei et al., 2013) and her spouse's level of education (Jouybari L et al., 2012) were reported to be directly and significantly related to the quality of life during pregnancy; however, in some other studies, the woman's own level of education (F. Abbaszadeh et al., 2009; Azizi et al., 2011; Makvandi \& Etemadi Kermani, 2012; Zahedi \& Deris, 2014), spouse's support (Zahedi \& Deris, 2014) and spouse's employment and level of education (Azizi et al., 2011; Zahedi \& Deris, 2014) and the household income (Jouybari L et al., 2012; Zahedi \& Deris, 2014) were not related significantly to the quality of life.

Some articles reported a significant reduction in the quality of life with the mother's increased age (F. Abbaszadeh et al., 2009; Jouybari L et al., 2012; Rezaei et al., 2013; Zahedi \& Deris, 2014), gestational age (F Abbaszadeh et al., 2009), parity and number of successful births (F. Abbaszadeh et al., 2009; Mousavi et al., 2012; Rezaei et al., 2013; Zahedi \& Deris, 2014) and pregnancy BMI (Safarzadeh et al., 2013) and with a case of high-risk pregnancy (Ahmadi et al., 2014; Mirmohammadaliei et al., 2007; Payamani et al., 2009) or in the case of residing in rural areas (Naseem et al., 2011); however, other studies found no relationships between quality of 
life in pregnant women and the mother's age (Azizi et al., 2011; Makvandi \& Etemadi Kermani, 2012), gestational age (Jouybari L et al., 2012; Makvandi \& Etemadi Kermani, 2012), parity and number of successful births (Azizi et al., 2011; Jouybari L et al., 2012; Makvandi \& Etemadi Kermani, 2012), pre-pregnancy and pregnancy BMI (Jouybari L et al., 2012), a case of high-risk pregnancy (Mohaddesi et al., 2014) and area of residence (urban or rural areas) (Jouybari L et al., 2012; Makvandi \& Etemadi Kermani, 2012).

Another factor investigated was the mother's employment status; however, different studies reported contradictory results in relation to this factor. Two studies found no significant relationships between the mother being employed and quality of life (F. Abbaszadeh et al., 2009; Azizi et al., 2011; Jouybari L et al., 2012), while one study reported an improved quality of life if the mother was employed (Rezaei et al., 2013) and another one reported a reduced quality of life in this case (Zahedi \& Deris, 2014).

\section{Discussion}

The review of the literature showed that, just as in other countries, studies conducted in Iran had also used general tools to assess quality of life during pregnancy due to the lack of a specific tool designed for this purpose. Despite their confirmed validity, these tools may not be appropriate for this purpose, since they are extensive assessment tools that have been designed to cover the most common areas of quality of life in the majority of the population. The problem with these general tools is that they neglect the dimensions that are relevant to specific groups of people, such as pregnant women, and therefore, fail to identify major post-treatment or post-intervention clinical changes (Mogos, August, Salinas-Miranda, Sultan, \& Salihu, 2013).

The number of tools used in these studies poses another challenge, since the data collected through the different tools cannot be compared in order to allow for cumulative results to form and present adequate information on the quality of life in pregnant women in Iran. Nonetheless, studies conducted in other countries have not reported a general quality of life score either. Although most experts believe that this score provides policy-makers with a summary of the changes occurred in the quality of life, using it for this purpose will not be rational, as dimensions with a greater number of items will have a greater weight, and as adding up the scores from different constructs is not scientifically grounded (Nejat, 2008). Nevertheless, since the majority of Iranian studies examining quality of life have used the SF-36 to report a range of changes in the quality of life score in pregnant women (from $61.18 \pm 13.21$ to $66.48 \pm 15.57$ ), it can be concluded that quality of life in Iranian pregnant women is medium and considered lower than the quality of life score among the general population of Iranian women (F. Abbaszadeh et al., 2009).

In terms of the factors associated with quality of life, the results of previous studies conducted in Iran were almost consistent with the results obtained in other countries, and factors such as the pregnancy being wanted ( $\mathrm{Li}$ et al., 2012; Wang, Liou, \& Cheng, 2013), a high level of education (Da Costa et al., 2010; Li et al., 2012; Wang et al., 2013) and a high socioeconomic status (Ramírez-Vélez, 2011) were associated with an improved quality of life. Instead, an increased rate of depression (Da Costa et al., 2010; Li et al., 2012; Nicholson et al., 2006), anxiety (Da Costa et al., 2010) and sleep disorders (Da Costa et al., 2010), life events (Da Costa et al., 2010), complicated pregnancies (Da Costa et al., 2010), a history of medical problems (Da Costa et al., 2010) and an increased BMI and gestational age (Li et al., 2012) were associated with a poor quality of life during pregnancy. In addition, the mother's age and occupational status (Li et al., 2012; Wang et al., 2013) were factors that produced contradictory results, just as was the case in Iranian studies. In a study by Lee et al., a reduction in age caused the score of the psychological dimension of quality of life to reduce and the score of the physical dimension to increase ( $\mathrm{Li}$ et al., 2012), which may be attributed to the mother's lack of control over her emotions at younger ages and with less intellectual maturity. Wang et al., however, found no relationships between age and the different dimensions of quality of life (Wang et al., 2013).

In one study, working mothers scored higher on the psychological, social and general health dimensions of quality of life compared to non-working mothers, but no significant differences were observed between them in the physical dimension (Wang et al., 2013); another study, however, reported lower scores in the physical dimension of quality of life in working mothers ( $\mathrm{Li}$ et al., 2012). The financial independence gained by working may improve women's psycho-social health in such a way that they overlook work-related physical problems. A reason for the disparity of the findings might be the differences in the type of occupation held by women in different countries. In some countries, women are forced to work long hours and perform heavy and exhausting tasks, which can harm their physical health.

In general, it can be argued that cultural differences between a country's population and also between different countries' populations can lead to conflicting results. The mutual effect of different underlying factors on one another and on the results of the study should not be overlooked, as conflicting results may be achieved 
depending on the differences in the number and type of variables under examination and the sample size. The limited number of studies conducted on this subject necessitates further studies on the quality of life in pregnant women in order to achieve more accurate results.

Limitations of the present study include the diversity of the groups studied in the different articles, which included different populations of pregnant women with different sets of problems. Moreover, given the small number of articles written about women with normal pregnancies, all the articles on this subject were reviewed regardless of the differences in their target populations. A strength of the present study was that it was one of the first efforts in Iran to examine the quality of life in pregnant women, the factors associated with it and the tools used to measure it.

The results of the present study showed a medium quality of life in pregnant women in Iran; it should be noted, however, that these results were obtained with the use of general tools for measuring quality of life in different populations. Another important finding of the study was the lack of a specific tool for measuring quality of life in pregnant women in spite of the different needs of this group during this period. The design of a specific localized tool to assess quality of life in pregnant women thus appears essential.

Despite showing the relationship between quality of life in pregnant women and several influential factors, no definitive conclusions can be drawn due to the insufficient number of studies conducted on some of the factors. More extensive studies are therefore required to identify the factors associated with quality of life in pregnant women divided by the distinct problems faced during this period. Qualitative studies are also required for achieving a profound understanding of the factors associated with the quality of life in pregnant women. Identifying these factors can help the design and implementation of effective interventions aiming to improve the quality of life in pregnant women.

\section{Acknowledgments}

The authors would like to express their gratitude to all the colleagues and authors whose valuable contributions to the discussion of the quality of life in pregnant women were used in the present study.

\section{Conflict of Interest}

The authors declare that there is no conflict of interests regarding the publication of this paper.

\section{References}

Abbaszadeh, F., Baghery, A., \& Mehran, N. (2009). Quality of Life among Pregnant Women. Hayat, 15(1), 41-48.

Abbaszadeh, F., Kafaei Atrian, M., Masoudi Alavi, N., Bagheri, A., Sadat, Z., \& Karimian, Z. (2013). Relationship between quality of life and depression in pregnant women. Nurs Midwifery Stud, 2(2), 193-197. http://dx.doi.org/10.5812/nms.8518

Ahmadi, S. E., Montazeri, A., Mozafari, R., Azari, A., Nateghi, M. R., \& Ashrafi, M. (2014). Health-Related Quality of Life and Primi-Gravid: A Comparative Study of Natural Conception and Conception by Assisted Reproduction Technologies (ARTs). Int J Fertil Steril, 8(2), 167-174.

Azizi, A., Amirian, F., pashaei, T., \& Amirian, M. (2011). Prevalence of unintended Pregnancy and its Relationship with Health-related quality of Life for Pregnant Women's in Salas city, Kermanshah- Iran. 2007. Iranian Journal of Obstetrics Gynecology and Infertility(5), 24-29.

Calou, C. G. P., Pinheiro, A. K. B., Oliveira, M. F. D., Aquino, P. D. S., \& Antezana, F. J. (2014). Health related quality of life of pregnant women and associated factors: an integrative review. Health, 6(18), 2375-2387. http://dx.doi.org/10.4236/health.2014.618273

Da Costa, D., Dritsa, M., Verreault, N., Balaa, C., Kudzman, J., \& Khalifé, S. (2010). Sleep problems and depressed mood negatively impact health-related quality of life during pregnancy. Archives of Women's Mental Health, 13(3), 249-257. http://dx.doi.org/10.1007/s00737-009-0104-3

Forger, F., Ostensen, M., Schumacher, A., \& Villiger, P. M. (2005). Impact of pregnancy on health related quality of life evaluated prospectively in pregnant women with rheumatic diseases by the SF-36 health survey. Ann Rheum Dis, 64(10), 1494-1499. http://dx.doi.org/10.1136/ard.2004.033019

Ghanei Gheshlagh, R., Toloeipoor Lanjavani, t., Lazari, N., \& Moslemi, B. (2014). Comparison of the quality of life in pregnant women with and without restless legs syndrome. Journal of Clinical Nursing and Midwifery, $3(1), 54-61$.

Hama, K., Takamura, N., Honda, S., Abe, Y., Yagura, C., Miyamura, T., . . A Aoyagi, K. (2008). Evaluation of 
Quality of Life in Japanese Normal Pregnant Women. Acta Medica Nagasakiensia, 52(4), 95-99. http://dx.doi.org/10.11343/amn.52.95

Higginson, I. J., \& Carr, A. J. (2001). Measuring quality of life: Using quality of life measures in the clinical setting. Bmj, 322(7297), 1297-1300. http://dx.doi.org/10.1136/bmj.322.7297.1297

Jouybari L, Sanagou A, \& Chehreh Gosha M. (2012). The Quality of Pregnant Women Life with Nausea and Vomiting. Qom University of Medical Sciences Journal, 6(2), 88-94.

Li, J., Mao, J., Du, Y., Morris, J. L., Gong, G., \& Xiong, X. (2012). Health-related quality of life among pregnant women with and without depression in Hubei, China. Matern Child Health J, 16(7), 1355-1363. http://dx.doi.org/10.1007/s10995-011-0900-z

Makvandi, S., \& Etemadi Kermani, A. (2012). Quality of life of pregnant women referred to health centers in Izeh (2010). Journal of Kermansha University of Medical Sciences(1), 37-42.

Mirmohammadaliei, M., Khakbazan, Z., Kazemnejad, A., \& Abbaszadeh, F. (2007). Comparison of Quality of Life and Depression among Women with Normal and High Risk Pregnancies. Hayat, 13(1), 35-42.

Mogos, M. F., August, E. M., Salinas-Miranda, A. A., Sultan, D. H., \& Salihu, H. M. (2013). A Systematic Review of Quality of Life Measures in Pregnant and Postpartum Mothers. Appl Res Qual Life, 8(2), 219-250. http://dx.doi.org/10.1007/s11482-012-9188-4

Mohaddesi, H., Bahadory, F., khalkhali, H. R., \& Baghi, P. (2014). Comparison of quality of life in low risk pregnant with high risk pregnant women in perinatology clinic of kowsar ward Shahid Motahari hospital in Urmia 2013,. Scientific Journal of Hamadan Nursing and Midwifery Faculty, 21(4), 69-95.

Montazeri, A., Goshtasebi, A., Vahdaninia, M., \& Gandek, B. (2005). The Short Form Health Survey (SF-36): translation and validation study of the Iranian version. Qual Life Res, 14(3), 875-882. http://dx.doi.org/10.1007/s11136-004-1014-5

Mortazavi, F., Mousavi, S. A., Chaman, R., \& Khosravi, A. (2014). Maternal quality of life during the transition to motherhood. Iran Red Crescent Med J, 16(5), e8443. http://dx.doi.org/10.5812/ircmj.8443

Mousavi, S. A., Mortazavi, F., Chaman, R., \& Ajami, M. S. (2012). Comparing the quality of life and psychological state of multiparous and primiparous women in ante-and postnatal periods: A cohort study. Journal of Kermanshah University of Medical Sciences, 17(5), 332-335.

Naseem, K., Khurshid, S., Khan, S. F., Moeen, A., Farooq, M. U., Sheikh, S., . . Yawar, A. (2011). Health related quality of life in pregnant women: a comparison between urban and rural populations. $J$ Pak Med Assoc, 61(3), 308-312.

Nedjat, S., Montazeri, A., Holakouie, K., Mohammad, K., \& Majdzadeh, R. (2008). Psychometric properties of the Iranian interview-administered version of the World Health Organization's Quality of Life Questionnaire (WHOQOL-BREF): a population-based study. BMC Health Serv Res, $8,61$. http://dx.doi.org/10.1186/1472-6963-8-61

Nejat, S. (2008). Quality of Life and its Measurement. Iranian Journal of Epidemiology, 4(2), 57-62.

Nicholson, W. K., Setse, R., Hill-Briggs, F., Cooper, L. A., Strobino, D., \& Powe, N. R. (2006). Depressive symptoms and health-related quality of life in early pregnancy. Obstet Gynecol, 107(4), 798-806. http://dx.doi.org/ 10.1097/01.aog.0000204190.96352.05

Nik-Azin, A., Nainian, M. R., Zamani, M., Bavojdan, M. R., Bavojdan, M. R., \& Motlagh, M. J. (2013). Evaluation of sexual function, quality of life, and mental and physical health in pregnant women. $J$ Family Reprod Health, 7(4), 171-176.

Payamani, F., Foroughi, S., Kamali, M., Goodarzi, F., Miri, M., Bayat, M., \& Seyyed Emami, R. (2009). Compare the quality of life in women with normal and high risk pregnancy. Aflak, 5(14,15), 59-62.

Ramírez-Vélez, R. (2011). Pregnancy and health-related quality of life: a cross sectional study. Colombia Médica, 42(4), 476-481.

Rezaei, E., Moghadam, Z. B., \& Saraylu, K. (2013). Quality of life in pregnant women with sleep disorder. $J$ Family Reprod Health, 7(2), 87-93.

Safarzadeh, A., Boryri, T., Khojasteh, F., \& NavvabiRigi, S. (2013). Evaluation of Quality of Life and Pregnancy Outcome in Overweight Pregnant Women in Zahedan. J Pain Relief, 2:124.

Shishehgar, F., \& Payman, A. (2009). Characteristics of nausea and vomitingin pregnancy and its association 
with quality of life Journal of Holistic nursing and midwifery(61), 16-21.

Shishehgar, F., \& Payman, A. (2010). Association of vomiting in pregnancy with body mass index and quality of life. Medical Journal of Hormozgan University, 13(4), 270-276.

Shishehgar, S., Mahmoodi, A., Dolatian, M., Mahmoodi, Z., Bakhtiary, M., \& Alavi Majd, H. (2013). The Relationship of Social Support and Quality of Life with the Level of Stress in Pregnant Women Using the PATH Model. Iran Red Crescent Med J, 15(7), 560-565. http://dx.doi.org/10.5812/ircmj.12174

Testa, M. A., \& Simonson, D. C. (1996). Assesment of quality-of-life outcomes. N Engl J Med, 334(13), 835-840. http://dx.doi.org/10.1056/nejm199603283341306

Vachkova, E., Jezek, S., Mares, J., \& Moravcova, M. (2013). The evaluation of the psychometric properties of a specific quality of life questionnaire for physiological pregnancy. Health Qual Life Outcomes, 11, 214. http://dx.doi.org/10.1186/1477-7525-11-214

Vallim, A. L., Osis, M. J., Cecatti, J. G., Baciuk, E. P., Silveira, C., \& Cavalcante, S. R. (2011). Water exercises and quality of life during pregnancy. Reprod Health, 8, 14. http://dx.doi.org/10.1186/1742-4755-8-14

Wang, P., Liou, S. R., \& Cheng, C. Y. (2013). Prediction of maternal quality of life on preterm birth and low $\begin{array}{llllll}\text { birthweight: a longitudinal study. BMC Pregnancy Childbirth, } 13, & 124 .\end{array}$ http://dx.doi.org/10.1186/1471-2393-13-124

World Health Organization. (1996). World Health Organization's Quality of Life group: WHOQOL-BREF Introduction, Administration, Scoring and Generic Version of the Assessment, Field Trial Version. .

Zahedi, M., \& Deris, F. (2014). The quality of life in pregnant women in Farokhshahr city, 2012. Journal of Clinical Nursing and Midwifery, 3(3), 63-69.

\section{Copyrights}

Copyright for this article is retained by the author(s), with first publication rights granted to the journal.

This is an open-access article distributed under the terms and conditions of the Creative Commons Attribution license (http://creativecommons.org/licenses/by/3.0/). 